\begin{tabular}{|c|l|}
\hline Title & Heat as a Tracer for Examining Depth-Decaying Permeability in Gravel Deposits \\
\hline Author(s) & Sakata, Y oshitaka \\
\hline Citation & $\begin{array}{l}\text { Groundwater, 53(S1), 21-32 } \\
\text { https://doi.org/10.1111/gwat.12236 }\end{array}$ \\
\hline Issue Date & 2015-04 \\
\hline Doc URL & http://hdl.handle.net/2115/61038 \\
\hline Rights & $\begin{array}{l}\text { This is the peer reviewed version of the following article: Groundwater, Volume 53, Issue S1, pages 21-32, A pril 2015, } \\
\text { which has been published in final form at http://0nlinelibrary.wiley.com/doi/10.1111/gwat.12236/abstract. }\end{array}$ \\
\hline Type & article (author version) \\
\hline File Information & Final manuscript for HuscA P.pdf \\
\hline
\end{tabular}

Instructions for use 


\section{Heat as a tracer for examining depth-decaying permeability in gravel deposits}

3

4

5

6

7

8

\section{Yoshitaka Sakata}

First affiliation: Division of Earth and Planetary Dynamics, Faculty of Science, Hokkaido University

North-10, West-8, Kita-ku, Sapporo, Hokkaido 060-0810, Japan

Second affiliation: Geotechnical Department, Division of Environmental Engineering, Docon Co., Ltd

1-5 Atsubetsu-chuo, Atsubetsu-ku, Sapporo, Hokkaido 004-8585, Japan

E-mail: yoshitaka_sakata@mail.sci.hokudai.ac.jp

Telephone/Fax: +81-11-801-1570

The author has no conflicts of interest to disclose.

\section{Abstract}

Depth dependence of permeability can appear in any geologic setting; however, vertical trends

in alluvial gravel deposits are poorly understood because of the high variability of hydraulic

conductivity $K$ in monotonic sequences. This paper examines the sensitivity of depth-decaying permeability through heat transport simulation around a river's losing reach in the Toyohira River alluvial fan, Japan. Observed variations in groundwater temperature indicate that heat fluxes are dominant in the shallow zone, despite a vertical hydraulic gradient. In eight cases with different conditions (presence or absence of exponential decay trend, large or small variogram range, and cell isotropy or anisotropy) $1,000 \mathrm{~K}$ realizations are stochastically generated throughout a cross-sectional 
model. The groundwater flow and heat transport are transiently calculated, and the averaged root

mean square error $\overline{R M S E}$ is used for sensitivity comparison. The variance of $\overline{R M S E}$ shows that small

$\overline{R M S E}$ realizations are effectively reproduced with vertical trend assumed. Plausible realizations of $\overline{R M S E}$ below a given threshold were obtained only when a vertical trend was assumed. The most plausible realization almost completely matched the observations. However, the number of plausible realizations per case was $\leq 10$ and the median $\overline{R M S E}$ were insensitive to all the conditions. Statistical testing suggested that these plausible realizations may be statistically significant, aiding in generating a connected $K$ zone for high heat flows. The cell anisotropy condition had the smallest effect on the simulation. Thus, effective modeling of the vertical trend contributes to heat transport; however, the model's efficiency is low without detailed information about the sedimentary structure.

\section{Introduction}

Depth-dependence of the permeability resulting from depositional and post-depositional processes may be found in any type of geologic formation. Geologic processes such as deltas, alluvial fans, and fluvial flows create unique patterns of hydrogeologic structure, not only in the 
lateral direction but also vertically (Freeze and Cherry 1979). In alluvial fans, for example, increasing coarsening and fining with depth are typically seen as a result of progradation, retrogradation, and basin subsidence (Neton et al. 1994). On a smaller scale, streambeds may also exhibit vertical trends in grain size, probably related to hydraulic conductivity K (Marion et al. 2008; Chen 2011). Post-depositional processes also affect geological formation: compaction with buried depth, diagenesis, metamorphism, chemical cementation, and other processes (Domenico and Schwartz 1990; Ingebritsen et al. 2006). Such permeability decay with depth significantly affects groundwater flow systems not only on a regional scale (Saar and Manga 2004; Jiang et al. 2009), but also at multiple scales including hyporheic zones (Zlotnik et al. 2011). Permeability decay with depth was also discussed in relation to groundwater transport and residence time, as well as flow (Cardenas and Jiang 2010; Jiang et al. 2010a).

In a coarse sediment mixture, $K$ is sensitive to changes in porosity, as shown in experimental studies (e.g., Koltermann and Gorelick 1995), laboratory tests (Major et al. 1997), and in-situ measurements (Yamaguchi and Nakamura 1994). However, the vertical trend of $K$ has rarely been determined in alluvial gravel deposits. Multilevel in-situ measurements of $K$ by pumping tests, slug 
tests, flow meters and other means are expensive and susceptible to many sources of error such as skin effects (Butler et al. 1994). Even with many in-situ measurements, the trend would not be necessarily detected because of the strong heterogeneity of $K$ on a smaller scale (e.g., Eggleston and Rojstaczer 1998). The sedimentary structure in alluvial gravel deposits consists of various components such as clast-supported gravel, matrix-supported gravel, and sand and finer materials (Rust 1979) and detailed information has only been obtained from a few outcrops and trenches (Jussel et al. 1994; Zappa et al. 2006). Even when detailed information is obtained, it is not valid to assume that the sedimentary texture of the upper layers extends to deeper layers. Generally, groundwater modeling of an unconsolidated gravel aquifer frequently assumes a constant value or homogeneity of $K$ in the vertical direction.

The purpose of this study is to assess the effect of a decreasing trend of $K$ on groundwater flow and transport in a numerical model of a typical monotonic gravelly aquifer. For this purpose, the author performed a sensitivity analysis of heat transport simulation around a losing river in the alluvial fan of the Toyohira River, Sapporo, Japan. Heat as a groundwater tracer is applicable in terms of robustness, convenience, and the low cost of field measurements (Anderson 2005). 
Groundwater temperature can also be used as an alternative to measuring solute components, owing to the analogy of the governing equations in groundwater transport (Langevin et al. 2008). In particular, the thermal properties of rocks and fluids can be specified a priori or may be less sensitive to heat transport simulation than $K$ (Anderson 2005), and thus temperature data can be used for estimating aquifer properties, especially as an inverse problem of $K$ (e.g., Woodbury and Smith 1988; Wang et al. 1989; Bravo et al. 2002).

However, using groundwater temperature as a tracer is not necessarily an advantage relative to other tracers, especially for inferring a $K$ pattern. Heat is transferred through the solid as well as the fluid, such that the thermal diffusivity of heat is several orders of magnitude larger than the molecular diffusion coefficient of other solute components (Domenico and Schwartz 1998). As a result, heat may be transformed mainly by conduction, including thermal diffusivity, and will be insensitive to convection, including groundwater velocity (i.e., $K$ ). In other words, measuring groundwater temperature would be effective in a situation of strong groundwater flow through relatively thick and permeable layers, for example, around a losing river in an alluvial fan. Several unique features such as the delay of the peak temperature arrival and the seasonal envelope are seen 
in temperature variations at observation wells near a losing reach (Constantz 2008).

This study focuses on a shallow heat transport system in a recharge zone along the Toyohira River. Temperature observations show heat transport is dominated near the water table, indicating a vertical decrease of $K$. Here, a Monte Carlo approach is applied to simulate the anisotropic heat transport system. One thousand realizations of $K$ were stochastically generated for eight study cases with a combination of the following three conditions (i.e., $2 \times 2 \times 2$ ): exponentially decreasing or constant vertical trend, large or small variogram of the residuals after detrending, and vertical isotropy or anisotropy at each cell. A coupled groundwater flow and heat transport model was constructed as a cross-sectional model of SEAWAT v.4. The average values of the root-mean-square residuals at the observation points were compared for the eight modeled cases. The sensitivity of the vertical trend and other heat transport simulation comparisons are discussed in terms of the probability of occurrence of the small error realizations.

\section{Materials and methods}

\section{Study site}


the northernmost island of Japan (Figure 1). The city of Sapporo is the largest in northern Japan, and

with population currently over 1.9 million and increasing. The alluvial fan extends across $\sim 35 \mathrm{~km}^{2}$, and is surrounded by Tertiary volcanic mountains to the west, hilly lands covered by Pleistocene volcanic ash to the east, and lowland to the north. The fan comprises a western Holocene fan (gray tone in Figure 1) 70-10 m above mean sea level (amsl) and an eastern Pleistocene fan (dark gray tone) $90-20 \mathrm{~m}$ asl. The Toyohira River is about $72.5 \mathrm{~km}$ long with a watershed area of about 900 $\mathrm{km}^{2}$. It flows south to north, almost through the center of the fan with an average inclination of about 7:1000, to the lowland around the Ishikari River (one of the main rivers in Japan). The median values of the daily mean and drought discharges of this river in the fan were 12.6 and $4.0 \mathrm{~m}^{3} / \mathrm{s}$, respectively, during the period 1974-2011. Synoptic discharge surveys (Sakata and Ikeda 2012) revealed that the losing rate $Q$ was about $1 \mathrm{~m}^{3} / \mathrm{s}$ between kilometer point (KP) 15.5 and KP 17.0, where KP is the distance units in kilometers along the river, as shown in Figure 1. $Q$ was about $80 \%$ of the total pumping rate of the city. The seepage rate per unit meter over distance $q$ was about 2 $\mathrm{m}^{3} /(\mathrm{m} \mathrm{hr})$. Similar seepage values have been estimated for other losing reaches in Japan. This large 
infiltration has been problematic for management of surface water use, especially during drought periods.

Figure 1c shows the water table elevation contours (bold lines) and the vertical hydraulic gradient contours (dashed lines) from a previous study (Sakata and Ikeda 2013a). The water table gently declines northward in the downstream direction, with horizontal hydraulic gradients in the order of magnitude of $10^{-2}$. The water table rises along the river between KP 15 and 17; this section includes the distinct losing section. On the other hand, the vertical hydraulic gradients are negative in the fan area, that is, downward fluxes of groundwater are dominant there because of groundwater withdrawals. The negative peak also extends to the river between KP 15.5 and 19.0, and the values in the losing section (K.P. 15.5-17.0) are ranged between -0.1 and -0.2 . The values are about one order of magnitude larger than the horizontal gradients of the water table. The anisotropy of hydraulic gradient also appears in the observation wells for this analysis, as described below. Various Quaternary sediments such as gravel, sand, silt, clay, and humus underlie the middle to distal parts of the Toyohira River alluvial fan. The hydrogeologic basement comprises Tertiary volcanic formations in the upper fan from KP 18, and Pleistocene marine sediments in the middle 
and distal fan. A subsurface gravel aquifer above the basement is divided into four sub-aquifers (Hu

et al. 2010): Pleistocene Nos. IV and III, and Holocene Nos. II and I. The lowermost Pleistocene No.

IV consists of alternating gravel, sand, and silt layers - the result of the transition of fluvial, delta, and shallow marine depositional systems. Both Pleistocene No. III and Holocene No. II aquifers consist mainly of alluvial fan gravel deposits, i.e., of poorly sorted andesite gravel with less than several percent fine content. The thickness of the gravel aquifer is over $100 \mathrm{~m}$ at the upper middle part of the Holocene fan, and less than $50 \mathrm{~m}$ at the distal part. Holocene No. I also consists of finer materials and appears only in the northern part of the fan (not in the study area).

\section{Field observation}

For the analysis data, the author conducted field observations of groundwater level and temperature in one deep well (DW-1) and three shallow wells (SW-1 to 3) along an off-stream transect at KP 16.6 (Figure 2). Distances from the center of the river channel are $76 \mathrm{~m}$ to DW-1, 80 $\mathrm{m}$ to SW-1, $140 \mathrm{~m}$ to SW-2, and $50 \mathrm{~m}$ to SW-3. The stratigraphic column at DW-1 shows a monotonic gravel sequence (i.e., Aquifers No. III and II) to a depth of about $63 \mathrm{~m}$. A finer layer 
appears at that depth, continuously lain with a gentle inclination to the east. The finer layer corresponds to the top of Pleistocene aquifer IV, and serves as a hydrologic basement of gravel deposits in the local area. Direct measurements of $K$ by slug tests (solid squares at DW-1) might show unobvious decrease of $K$ with depth because of the large variation of $K$ in the Holocene gravel aquifer. Sakata and Ikeda (2013b) estimated the effective hydraulic conductivity $\bar{K}$ (open squares) from the core properties. A moving average analysis (solid line) revealed a vertical trend from the surface down to $30 \mathrm{~m}$ depth, and was established as an exponential function of depth $z(\mathrm{~m})$ :

$$
\bar{K}=\bar{K}_{0} \exp (-A z)=10^{-2.3} \exp (-0.11 z) \quad \text { at } z<z_{0}
$$

where $\bar{K}_{0}$ is the average $\bar{K}$ value on the surface, from DW-1 and another borehole; $A\left(\mathrm{~m}^{-1}\right)$ is a decay exponent; and $z_{0}$ is the depth limit of the exponential decay $\left(z_{0}=30 \mathrm{~m}\right.$ in the fan). The depth was also equal to the boundary between the Holocene No. II and Pleistocene III aquifers (Hu et al. 2010). This exponential model was used in previous studies (Saar and Manga 2004; Jiang et al. 2009; Zlotnik et al. 2011; Cardenas and Jiang 2010; Jiang et al. 2010a) and verified in a theoretical study (Jiang et al. 2010b). However, the decay exponent in the fan was 10 to 1000 times that in consolidated rocks, $1 \times 10^{-2}$ to $1 \times 10^{-4} \mathrm{~m}^{-1}$ (Jiang et al. 2009). The exponent decay reduced the 
value of $K$ at $\mathrm{z}=30 \mathrm{~m}$ to only $1 / 25$ of its value on the surface. Thus, the previous study suggests that the large exponent decay may significantly affect the shallow systems of groundwater flow and transport. pressure transducer (HOBO U20 Water Level Data Logger U20-001-01; accuracy $\pm 0.05 \%$ ). At deep well DW-1, the hydraulic head and temperature were observed at $15 \mathrm{~m}$ (DW-1-1), and the groundwater temperature was also observed at two additional depths, $30 \mathrm{~m}$ (DW-1-2) and $60 \mathrm{~m}$ (DW-1-3) using a thermal sensor (HOBO Water Temperature Pro v2 Data Logger U22-001; accuracy $\pm 0.2^{\circ} \mathrm{C}$ ). The screen interval of DW-1 was $1 \mathrm{~m}$ between 63 and $64 \mathrm{~m}$ depth, and those of the shallow wells SW-1, SW-2, and SW-3 were a few meters below the water table. The set of deep well DW-1 and shallow well SW-1 (2 m apart) formed a piezometer nest. Observations were conducted from 10 June 2010 to 28 February 2011 (264 days). The river stage was observed at the upper gauging station of KP 17.8, and the data were converted to those measured at KP 16.6 using a linear relationship $\left(R^{2}=0.96\right)$. All the original data were acquired hourly, but daily average data were used in the analysis to smooth uncertain fluctuations, including measurement errors. 
Figure 3 shows the observed water level and temperatures of the groundwater and surface

water. The water table levels in the shallow wells were usually lower than the river stage, but among

them they varied almost in parallel. Sudden rises caused by precipitation were rarely seen during the observation period, indicating that the groundwater recharge depends mainly on surface water infiltration within the local area. The water table levels at SW-1 and SW-2 were nearly identical, and the water table at SW-3 was lower than at other shallow wells, although SW-3 was closer to the river channel. Thus, the average horizontal hydraulic gradients (dimensionless) from the river were substantially different, 0.007 at SW-1, 0.004 at SW-2, and 0.018 at SW-3. The hydraulic head at DW-1 was about 7-8 $\mathrm{m}$ lower than the water table at SW-1; the average vertical hydraulic gradient was -0.11 , indicating a downward flow. The magnitude was about one order larger than that of the horizontal hydraulic gradient, as shown in Figure 1c. The water-level variation at DW-1 was relatively smooth, and the seasonal fluctuation probably reflected the water cycle (e.g., reduced recharge in winter) and the intake of the city (e.g., pumping for cooling in summer). The surface water temperature varied daily and seasonally, reaching a low of $1.0^{\circ} \mathrm{C}$ on 18 December and a high of $20.6^{\circ} \mathrm{C}$ on 6 September (Figure 3b). In the well nearest the river, SW-3, the 
groundwater temperature almost matched the smoothed temperature of the surface water, probably

indicating preferential flows east of the river. The groundwater temperature at SW-1 and SW-2 showed smoother fluctuations and delayed peaks $\left(13.4^{\circ} \mathrm{C}\right.$ on 28 October at SW- 1 and $12.0^{\circ} \mathrm{C}$ on 2 December at SW-2). At the deep well DW-1, the groundwater temperatures fluctuated in a much narrower range than at the shallow wells, and the temperature at DW-1-3 at $60 \mathrm{~m}$ depth was constant at $10.3^{\circ} \mathrm{C}$, indicating an isothermal layer near the bottom, despite the large hydraulic gradient in the downward direction. In other words, the shallow heat transfer might be affected by permeability, in terms of Darcy's law.

\section{Heat transport model}

section similar to that of the observation transect. The SEAWAT v.4 simulation program (Thorne et al. 2006; Langevin et al. 2008) in Visual MODFLOW 2009.1 (Schlumberger) was used in this study.

Figure 4 illustrates the grid design and boundary conditions. The total length between SW-2 (left;

west) and SW-3 (right; east) was $190 \mathrm{~m}$ (lateral coordinate $x=-140 \mathrm{~m}$ to $50 \mathrm{~m}$ ), and the total depths 
varied between $54 \mathrm{~m}$ on the eastern side and 64 on the western side. The vertical grid spacing was 1

$\mathrm{m}$, except for the lowermost layer. The horizontal grid spacing was also $1 \mathrm{~m}$ between the river channel and SW-1 $(x=80 \mathrm{~m})$, and $5 \mathrm{~m}$ on the east and west sides. Anderson and Woessner (1992) recommended that the increase in cell widths in such finite-difference models should be no more than 1.5 times the original width. However, in this study the grid was designed so that the stochastic realizations of $K$ per 1-m regular grid were smoothly input into the numerical model. The inflow condition was set for the upper cells of the river channel $(x=-15 \mathrm{~m}$ to $5 \mathrm{~m})$ using the "River Boundary" function of MODFLOW. The river stage and temperature were variable in time as shown in Figure 3a (black line), and $K$ of the streambed was assumed to be $1 \times 10^{-2} \mathrm{~m} / \mathrm{s}$, which was sufficient to allow for water infiltration. The outflow boundaries on both sides were represented using the "Drainage Boundary" condition of MODFLOW rather than the "Constant Head Boundary.” This was because the constant head boundary compels unrealistic downward flows from the groundwater table to the bottom. The drainage elevations varied daily, and were linearly interpolated from the water table to the west of SW-2 or the east of SW-3 vertically downward according to the vertical hydraulic gradient between SW-1 and DW-1. No vertical flows and heat 
fluxes were assumed for the other upper cells based on the assumption that the seepage loss was the dominant recharge source within the local area. No flow and fluxes were also assumed for the

bottom cells based on the assumption that the permeability of the bottom fine layer was negligible.

The seasonal temperature profiles at DW-1 commonly showed that the temperature gradient was only about $0.3^{\circ} \mathrm{C} / 100 \mathrm{~m}$ at the bottom depth (Sakata 2013). The initial conditions of the hydraulic head and temperature were estimated from maps drawn manually from observation data at the start date, 10 June 2010.

\section{Stochastic realization of hydraulic conductivity}

This study generated stochastic realizations of $K$ following the modeling concept of a vertical trend on a scale of tens of meters, and small-scale heterogeneity on a 1-m scale. One simple way to apply this is to detect a trend, simulate the residuals, and then return to the trend (Nowak and Verly 2004). The logarithmic conductivity $Y[\log (\mathrm{m} / \mathrm{s})]$ was used instead of $K$, because $K$ was assumed to be log-normal (Domenico and Schwartz 1998; ASCE 2008). $Y(s)$ at any location $s(x, z)$ in the cross section is formulated as a sum of the trend component $M(z)$ and residual component $R(s)$ : 
$M(\mathrm{z})$ was assumed a function only of the depth $z(\mathrm{~m})$, and independent of distance x (m). $M(\mathrm{z})$ was

233

assumed a common logarithm of Equation (1), in which $\bar{K}_{0}$ was replaced by $10^{-3.07}$ as the value at the location of DW-1. $M(z)$ was also assumed to be constant below the limited depth $z_{0}$ as:

$$
M(\mathrm{z})=-3.07-0.047 \mathrm{z} \quad \text { at } z<30 \mathrm{~m}
$$

$M(\mathrm{z})=-4.50$

at $z \geq 30 \mathrm{~m}$

The equation also assumes heterogeneity with a vertical trend in Holocene aquifer no. II and

stationary heterogeneity in Pleistocene aquifer no. III. This study assumed $R(\mathbf{s})$ as a regional

variable with the same variogram throughout the analysis domain, as detailed geologic information for dividing the monotonic sequence was not obtained. Sequential Gaussian simulation (SGS) was used for its stochastic realization as in other sandy gravel aquifer modeling (Eggleston et al. 1996; Jang and Liu 2004; Lee et al. 2007). The SGS process has six steps (Deutsch and Journel 1998): 1) input the honor data (solid squares in Figure 2), which are equal to the estimates at the nodes. 2) Generate a random path though the grid nodes. 3) Select the first node in that path and estimate a mean and standard deviation at that node by normal or ordinary kriging based on the surrounding 
honor data. 4) Obtain a random value from the mean and standard deviation and set the value at the

node. 5) Include the newly simulated value as part of the honor data. 6) Repeat steps 2 to 5 until all the grid nodes have simulated values. The SGS in this study was performed using a free Fortran code sgsim in GSLIB (Deutsch and Journel 1998).

The realizations by SGS are significantly dependent on the variogram model. The variogram of $R(s)$ in the fan was previously formulated by Sakata (2013) who used 134 slug-test results and performed variogram analysis using original data of $R(s)$ and obtained a histogram that was approximately Gaussian at 95\% significance level. Consequently, a spherical anisotropic model of distance $h$ was obtained as:

$$
\gamma(h)=c+b\left[\frac{3}{2} \frac{h}{a}-\frac{1}{2}\left(\frac{h}{a}\right)^{3}\right]
$$

In Sakata (2013), the sill $b$ and nugget $c$ were determined to be nearly identical in the horizontal and vertical directions ( $b=1.0$ and $c=0.5$ ). The range $a$ differed in the $x$ and $z$ directions, $a_{\mathrm{x}}=1000 \mathrm{~m}$ in the lateral direction and $a_{\mathrm{z}}=20 \mathrm{~m}$ in the vertical. Such large range anisotropy was also observed in nature (Deutsch 2007). However, the estimated ranges may be too large on the local scale used in this analysis compared with other field studies (e.g., Hess et al. 1992; Rubin 2003). Gelhar (1993) 
summarized the correlation scales of horizontal and vertical $K$ on an overall scale less than $1 \mathrm{~km}$.

The relationship indicated that a correlation scale of $100 \mathrm{~m}$ was probably 10 to $20 \mathrm{~m}$ in the horizontal direction, and a few meters in the vertical direction (Figure 6.6 in the text of Gelhar). Thus, the author examined the residual variogram on two different scales, large ( $a_{\mathrm{x}}=1000 \mathrm{~m}$ and $a_{\mathrm{z}}$ $=20 \mathrm{~m})$ and small $\left(a_{\mathrm{x}}=10 \mathrm{~m}\right.$ and $\left.a_{\mathrm{z}}=2 \mathrm{~m}\right)$, in addition to the presence or absence of a vertical decreasing trend. The sill and nugget parameters were probably also different among the local and basin scales as well as the ranges. However, the values in the previous analysis were consistently used in this study because only eight $Y$ honor data were obtained in the cross section. The sill and nugget values generated a relatively random field of $K$ and the value of $K$ changed by several orders of magnitude between adjacent points. The variance of the $Y$ honor data was 1.2, which was nearly equal to the sum of the nugget and sill.

One thousand realizations of the residuals were generated on the 1-m regular grid throughout the cross-section for the two variogram ranges (large and small). Next, the logarithmic conductivity $Y(s)$ was obtained by adding the simulated residuals to the trend component (Equation (3)). For this process, another constant trend $M_{0}$ was also assumed instead of the vertical trend. $M_{0}$ 
was simply calculated at -4.17, as an integral average of Equation (3) from the surface to the bottom

of the aquifer at DW-1. Figure 5 shows extracted examples of the residuals (panels a and b) and the

resulting logarithm of $K$ (panels $\mathrm{c}$ to f). Panel c shows the most plausible realization from a total of 8000, as described below. The residuals were generated using the large (panel a) and small (panel b) variogram ranges, respectively. Both realizations demonstrate variability in about four orders of magnitude among the 1-m regular grids. These images also include slightly decreasing trends with depth as a result of the conditional simulation with the honor data at DW-1. The simulation that used the large-range condition (panel a) produced relatively continuous zones of high $K$ value (red and orange) and low $K$ value (light and dark blue). On the other hand, the small range condition (panel b) shows almost randomly patched zones, probably typical alluvial gravel deposits. The images of $Y$ (panels c and e) were obtained by adding the vertical trend to panels a and b, resulting in relatively high and low $Y$ values in the shallow and deep layers. The lower images (panels $d$ and $f$ ) were obtained by adding a constant mean to the same residuals, producing mostly vertical trends that are masked in the large heterogeneity. The stochastic realizations of $Y(\boldsymbol{s})$ were inversely log-transformed to $K(\mathbf{s})$, which was assigned 
to each cell in the numerical model. $Y(\mathbf{s})$ in the lowermost layer and on both sides of the 5-m-wide

cells was obtained by averaging all the $Y(\mathbf{s})$ values of the 1-m grid cells. In the final modeling step, the ratio of vertical/horizontal anisotropy was also considered for assessing further small-scale heterogeneity within a depth of $1 \mathrm{~m}$ (Freeze and Cherry 1979; Burger and Belitz 1997). The vertical/horizontal anisotropy ratio $R$ varies in space; therefore, individual values should be given at each cell. However, the author prepared two simplified cases in which all the cells had a constant isotropic ratio $(R=1)$ or were assigned an anisotropy value $(R=0.1)$. Other aquifer and fluid properties were assumed to be constant in this simulation. The total porosity was 0.2 and the specific storage was set to $10^{-5} \mathrm{~m}^{-1}$. The heat capacities and densities of the andesitic gravel deposits were $850 \mathrm{~J} / \mathrm{kg} /{ }^{\circ} \mathrm{C}$ and $2600 \mathrm{~kg} / \mathrm{m}^{3}$, and those of the fluid were 4183 and 1000, respectively. The thermal conductivities of the bulk and fluid were 2.5 and $0.6 \mathrm{~W} / \mathrm{m} /{ }^{\circ} \mathrm{C}$, respectively. The longitudinal and transverse thermal diffusivity values were 10 and 0.1 . These thermal parameters were less sensitive to the heat transport simulation than $K$ (Sakata 2013). The dependencies of the fluid density and viscosity on temperature were assigned from the literature (Voss 1984; Langevin et al. 2008). 


\section{Error estimation} 10 June 2010 through 28 February 2011 (264 days) with 24 time steps (hourly). The calculated temperature was extracted each day at six observation points, i.e., at three depths of DW-1 (index $j=$ $1,2,3)$ and at the three shallow wells, SW-1 $(j=4)$, SW-2 $(j=5)$, and SW-3 $(j=6)$. The model fitting in each realization was assessed by least squares; the fit between simulated values and field measurements was quantified using squared differences. The individual root mean square error square error $\overline{R M S E}$ was then obtained from the six values of the individual $\overline{R M S E}$ :

$$
\begin{aligned}
& \overline{R M S E}=\frac{1}{N_{w}} \sum_{1}^{N_{w}} R M S E_{j} \\
& \text { RMSE }_{j}=\sqrt{\frac{1}{N_{d}} \sum_{i=1}^{N_{d}}\left(T_{j}\left(t_{i}\right)-T_{j}^{*}\left(t_{i}\right)\right)^{2}}
\end{aligned}
$$

where $N_{\mathrm{w}}$ is the number of observation points for assessing the fit (6 here). $N_{\mathrm{d}}$ is the number of transient calculation outputs (264). $T^{*}\left(t_{i}\right)$ and $T\left(t_{i}\right)$ are the calculated and observed temperatures at each calculation time $t_{\mathrm{i}}$ ( $i=1$ to 264 day), respectively. The statistical values of the average $\overline{R M S E}$ 
study, the criterion of $\overline{R M S E}$ for a good match between the model and observations was defined as

$1.0^{\circ} \mathrm{C}$. The average range of the groundwater fluctuations is $6.52^{\circ} \mathrm{C}$; therefore, the normalized error of the criterion is about $15 \%(1.0 / 6.52)$. The author believes that obtaining an error range within about $10-20 \%$ is probably difficult in groundwater transport simulation. Indeed, the error estimator $\overline{R M S E}$ was affected not only by the comparison conditions but also by various factors such as measurement errors, uncertainty in initial and boundary conditions, and model restrictions in the cross section. Here, the criterion is considered to be suitable because it revealed a statistical discrepancy of $\overline{R M S E}$ among the eight study cases, and the calculated temperature time-series visually match those of the observations, as shown below. Consequently, the realizations of $\overline{R M S E}$ that were less than the criterion value were extracted as "plausible."

\section{Results}

\section{Error Statistics}

For each of the eight cases, Table 1 summarizes the statistical values of the $\overline{R M S E}$, median (Me), variance (Var), minimum value (Min), and the number of $\overline{R M S E}$ realizations less than $1^{\circ} \mathrm{C}(\mathrm{N}$ 
$\overline{\text { RMSE }}$ ) for 1000 realizations. Figure 6 shows the cumulative percentage curves of $\overline{R M S E}$ for each case.

Me was in a narrow range between $2.5^{\circ} \mathrm{C}$ and $2.9^{\circ} \mathrm{C}$, and was insensitive to any of the model conditions. This means that most of the realizations failed to calculate the high heat flow around the losing river. This was because $\overline{R M S E}$ was calculated at $2.92^{\circ} \mathrm{C}$ in the special case where the temperatures in all the cells did not vary from the initial condition. The actual average seepage rate from the river boundary was about $0.2 \mathrm{~m}^{3} /(\mathrm{m} \mathrm{hr})$, and the value was only one tenth of the observed seepage rate $q\left(2 \mathrm{~m}^{3} /(\mathrm{m} \mathrm{hr})\right)$. The root mean square errors of the groundwater head in the realizations were over about $1 \mathrm{~m}$ in the deep and shallow wells. The failures in most realizations were probably due to the limitation of Gaussian simulation in this study. Gaussian simulation cannot reproduce extremely high values of simulated variables (Koltermann and Gorelick 1996; Lee et al. 2007). However, the exchange of heat between the surface water and groundwater is dependent on such preferential flow paths such as buried channels (e.g., Woessner 2000). Moreover, in this study, the $Y$ honor data were limited to only one borehole and detailed geologic information around the losing river. This Monte Carlo approach using a total of eight thousands realizations indicated that the heat transport simulation may be inefficient unless the typical conduits of high heat flows are identified in 
advance, at least to an approximate extent.

Despite the low efficiency of the method, small $\overline{R M S E}$ values were frequently obtained as Var increased since Me was nearly equal in all the study cases. In Figure 6, when Var increased, the cumulative percentage curves of $\overline{R M S E}$ had relatively gentle slopes. The cases that had a vertical trend (red lines) had a more gentle slope than those without the trend (blue lines). The large variogram range (bold lines) also tended to produce a leftward shift in the area compared with the cases with a small range (thin lines), although the change appears smaller than that associated with the presence or absence of a vertical trend. The condition of cell anisotropy appears to have a smaller effect than the other two conditions. The relation of Min among the eight cases was opposite to that of Var; Min in the vertical trend cases was consistently smaller than in the constant trend cases, independent of the other conditions. Min in the large range cases was also smaller than in the small range cases, as well as in the vertical trend cases. However, the relation of Min with regard to cellisotropy and anisotropy was not obvious. Especially in the large range cases, Min of the cell-isotropy cases was nearly equal to that of the anisotropy case.

$N_{\overline{R M S E}}$ is another probability index that indicates how often plausible realizations were 
generated. As shown in Table 1, the largest $N_{\overline{R M S E}}$ was 10 in Case 2 . The second largest was 4 in

Case 1. The smallest number was 2 in Case 3. These cases were common in terms of the exponentially decaying pattern of $K$. No plausible realizations were achieved in the other study cases. This also indicates that modeling the exponentially decreasing trend may be essential for obtaining plausible realizations. However, no plausible realization was achieved in Case 4, which also contained a vertical trend as did Cases 1 through 3. Moreover, where plausible cases were found, their occurrence corresponds to a probability of $\leq 1 \%$ of the 1000 realizations. Thus, one might argue that $N_{\overline{R M S E}}$ in the latter three cases may not be as statistically significant as the other cases $\left(N_{\overline{R M S E}}=0\right)$. To verify this, a statistical test was performed on the hypothesis that $N_{\overline{R M S E}}$ was obtained rarely (less than or equal to $1 \%$ ) but randomly, that is, independent of the vertical trend, variogram range, and cell anisotropy (i.e., the Poisson distribution). The probability $P_{0}$ of no occurrence $\left(N_{\overline{R M S E}}=0\right)$ among $n$ trials was simply calculated with the mean probability $p: P_{0}=(1-$ $p)^{n}$. For the statistical hypothesis, the mean probability of the occurrence of $\overline{R M S E}<1^{\circ} \mathrm{C}$ in 1000 samples was assumed to be $p_{1}=0.002\left(N_{\overline{R M S E}}=2\right.$ in Case 3), $p_{2}=0.004\left(N_{\overline{R M S E}}=4\right.$ in Case 1$)$, and $p_{3}$ $=0.01\left(N_{\overline{R M S E}}=10\right.$ in Case 2). Thus, the probabilities of $N_{\overline{R M S E}}=0$ were $0.14,0.02$, and $<0.01$, 
respectively. For $N_{\overline{\text { RMSE }}}=2$ in Case 3, the hypothesis was accepted with a significance level of 95\%.

This indicates that Case 3 with a vertical trend, small variogram range, and cell anisotropy conditions may not be different in terms of reproducing plausible realizations from other cases of $N$ $\overline{R M S E}^{\text {RMS }}=0$. On the other hand, the hypothesis was rejected for $N_{\overline{\text { RMSE }}}=4$ in Case 1 and $N_{\overline{\text { RMSE }}}=10$ in Case 2. Thus, it can be concluded that the plausible realizations of $\overline{R M S E}<1^{\circ} \mathrm{C}$ were statistically significant in Cases 1 and 2, i.e., those with a combination of the vertical trend and large variogram range, relative to the other cases.

\section{Temperature time series}

Figure 7 shows the calculated temperature time-series for the smallest $\overline{R M S E}$, i.e., $\mathrm{Min}$, realizations in each study case. At the deepest point DW-1-3, all the results were nearly identical with the observation of a constant temperature of $10.1^{\circ} \mathrm{C}$. This indicates that the isothermal layer was independent of the spatial variability of $K$, and was realized based on the boundary conditions. For the shallow SW-3 well, all the calculations also achieved almost satisfactory matching with observations. The average $\overline{R M S E}$ values were obtained for individual $\overline{R M S E}_{j}$ of six points, but the 
averaging was most affected by $\overline{R M S E}_{6}$ at SW-3 because $\overline{R M S E}{ }_{6}$ varied the most among the different realizations, with relation to large fluctuations of groundwater temperature as a result of high heat flows.

The temperatures observed in the shallow wells SW-1 and SW-2 showed typically smooth fluctuations with different peak delays. All the results of Cases 1 to 5 calculated the typical delay at a relatively close shallow well, SW-1. In Cases 6 and 7 the peak delay was longer while in Case 8 the calculated temperature at SW-1 was almost constant, indicating no heat fluxes in the west direction. At SW-2, however, the peak delay was in good agreement with the observations in Cases 1, 2, and 3. The results were equal to those in which the plausible realizations were obtained $\left(N_{\overline{\text { RMSE }}}>0\right)$. On the other hand, in Cases 4 to 8, almost no fluctuation indicated that most of the heat fluxes infiltrated into the deeper layer, due to downward flows.

Finally, Cases 1, 2, and 3 were compared at the deep well DW-1-1 and DW-1-2. Case 1 showed little fluctuations compared with the observation at DW-1-2 while in Case 3, very little fluctuations were calculated at DW-1-1. Only the realization in Case 2 provided some fluctuations at both DW-1-2 and DW-1-1 as a result of heat flow toward these points. Therefore, the realization in 
Case 2, as previously shown in Figure 5c, may be the most plausible among the 8000 realizations.

The average seepage rate in the realization was $2 \mathrm{~m}^{3} /(\mathrm{m} \mathrm{hr})$, which was equal to the observed rate $q$.

The RMSE of the hydraulic head was only $0.12 \mathrm{~m}$ in SW-1 and $0.6 \mathrm{~m}$ in DW-1. These values are

within the accepted values of anisotropic heat transfer around the losing river. Note that the calculated temperatures at DW-1-2 were not well matched because the heat fluxes from the previous winter occurred within the calculation period.

\section{Discussion}

This study used heat as a groundwater tracer for examining depth-decaying permeability in a monotonic gravel aquifer, in the Toyohira River alluvial fan. Around the losing river reach, groundwater temperature was applied as a tracer for the sensitivity analysis of $K$. Heat transport simulation was performed using stochastic realizations of $K$. Another unique aspect of this study was the simulation of the spatial variability of $K$ using a combination of multiple-scale heterogeneity: the exponential decreasing trend with depth on a scale of tens of meters, the stochastic residuals between 1-m regular grids, and cell anisotropy within a depth of $1 \mathrm{~m}$. One thousand realizations of the 
residuals were generated by SGS and converted to $Y$ by adding the trend component. Back log-

transformed $K$ were input to the SEAWAT model in eight comparison cases with different conditions: the presence or absence of vertical trend, large or small variogram range, and cellisotropy or anisotropy. The average $\overline{R M S E}$ at six observation points was used for comparison with the observations, and the statistical parameters were compared. The variance of the $\overline{R M S E}$ indicates that the cases with the vertical trend condition had smaller $\overline{R M S E}$ values. Plausible realizations of $N_{\overline{R M S E}}$ were obtained only in the cases that simulated a vertical trend. When the vertical trend was assumed, the plausible realizations were obtained in cases of either large or small ranges, and cell isotropy or anisotropy. The relative sensitivity is noteworthy, because the change of $K$ by vertical trend (one to two orders of magnitude) was smaller than the random variation by SGS (four orders of magnitude). In this study, several realizations with the smallest $\overline{R M S E}$ values provide a good match with observations when the vertical trend is included. The most plausible model showed an almost perfect match to the observations in terms of groundwater temperature, hydraulic head, and seepage rate. Therefore, modeling the exponential decrease may be an important factor in the description of the shallow heat transport, and of other 
solute components such as artificial contaminants infiltrated from the surface.

In this study, however, the effect of modeling the vertical trend was not pronounced because the number of plausible realizations $N_{\overline{\text { RMSE }}}$ was only ten or less, i.e., $1 \%$ of 1000 realizations. The mean $\overline{R M S E}$ was insensitive to the introduced conditions and nearly equal to the value for the case when the groundwater temperature is assumed to remain steady at its initial level. These results also provided much lower seepage rates from the river boundary, compared with the observations. In particular, a statistical test suggested that $N_{\overline{R M S E}}$ may be significant only when the vertical trend and large range conditions are present. The large range condition was particularly helpful for SGS in reproducing a high- $K$ connected area as a conduit. Thus, the vertical trend was probably essential to the anisotropic heat transport system; however, a sedimentary structure that included preferential flow paths is also required for a high heat flow system around the losing river. In this study, the preferential flow paths were specified among thousands of realizations with a (maybe unrealistic) large range condition. This approach was too inefficient, and the simulations were validated using a limited number of observation data (only six points in this study). Additional information about zones of increased groundwater flow may be combined with the stochastic modeling to improve the 
efficiency of obtaining plausible realizations. For example, a delineation of the hydrofacies, including preferential flow paths (e.g., open-framework gravel) can be obtained near the surface. The shallow information is then interpolated to the deeper layers, based on data from a number of high-quality cores, a high-resolution geophysical survey (e.g., Regli et al. 2002; Bennett et al. 2006) and other advanced methods such as hydraulic tomography (Berg and Illman 2011). In future work, indicator simulation or other advanced methods could provide good realizations of complex heterogeneity, as shown in several innovative studies (Weissmann et al. 1999; Felletti et al. 2006; Ramanathan et al. 2010; Guin et al. 2010). These field and numerical methods are probably applicable but practically limited, as suggested in this paper. Another approach based on calibration such as the parameter estimation method PEST may be effective when field data are limited. The vertical/horizontal ratio of the anisotropy of $K$ at each 1-m cell helps prevent downward groundwater flow, as well as the vertical decreasing trend on a scale of tens of meters. This study also showed that the $N_{\overline{R M S E}}$ in Case 2 with anisotropy was more than double the $N_{\overline{R M S E}}$ in Case 1 with isotropy. The most plausible realization included the anisotropic condition; however, the statistical test suggested that the effect of the cell anisotropy condition was not larger than that of the other two 
comparison conditions. The heterogeneity within $1 \mathrm{~m}$ was probably insensitive to the shallow heat

transport on this scale. In this study, the vertical/horizontal anisotropy was assumed to be constant throughout the area even though the value actually varies in space. Modeling the cell anisotropy will also be required in future work.

Finally, several other uncertainties and limitations in the present analysis are discussed. First, the exponential decay trend (Equation (1)) is probably unique to this alluvial fan. Other gravelly aquifers may show different magnitudes of decay exponent, other functions (e.g., a simple linear trend), or unobvious trends with a small exponent. In this heat transport simulation, similar conclusions may be derived using a linear trend fitted to the exponential model in the shallow depth. The vertical change of $K$ must be established individually at each site using multi-level in-situ tests, core-analysis, and other methods. Additionally, the number of observation points (six points in this study) was probably not sufficient for inferring the complex heterogeneity in the gravel deposits. To improve the reliability of the results, several shallow wells should be installed between SW-1 and SW-2, and at least one deep well in addition to DW-1. The error criterion should be changed to a more reasonable one, considering several other factors of error. Finally, restricting the model within 


\section{Conclusions}

the cross section may affect the small number of plausible realizations, because the generated $K$ patterns act as if the domain was extended infinitely in the y plane. 3D modeling would be required for more rigorous treatment, although its computational cost may be a limiting factor.

In this study heat was used as a groundwater tracer to analyze the modeling of the vertical

decrease of $K$ in monotonic gravel sequences of the Toyohira River alluvial fan. The observations

indicated a dominant heat flux in the shallow zone, despite a vertical hydraulic gradient, implying a

hydrogeologic structure, including a vertical decrease. Heat transport simulation was performed

using stochastic realizations of $K$, based on the Monte Carlo approach. One thousand realizations of

$K$ were reproduced using a combination of the exponentially decreasing trend and small-scale

heterogeneity generated by SGS. Eight different conditions were modeled: the presence or absence

of a vertical trend, large or small variogram range, and cell isotropy or anisotropy. The averaged root

mean square error $\overline{R M S E}$ at six observation points was calculated for each realization, and the

statistical values were compared. 
realizations the seepage rate from the river boundary was much smaller than in the observations.

This means that the SGS did not generate reliable preferential flow paths for high heat flow with the

limited honor data available. Despite its inefficiency, plausible realizations with $\overline{R M S E}$ below the

threshold (the criterion temperature of $1^{\circ} \mathrm{C}$ ) were obtained when the vertical trend condition was

present, although the systematic change of $K$ with depth was two orders of magnitude smaller than

the small-scale heterogeneity. Several realizations with vertical trend agreed with the observations,

and the most plausible one was almost a complete match in terms of groundwater temperature,

hydraulic head, and seepage rate. This indicates that the vertical trend effectively contributed to the anisotropic heat transport system.

However, there were fewer than ten plausible realizations among the 1000 realizations,

512 including those with the vertical decrease. A statistical test suggests that the plausible realizations

with the vertical trend and large variogram range conditions may be statistically significant. The variogram range condition was probably unrealistic, but aided in generating a high-connected zone. 
518 heat transport, detailed information of the smaller-scale heterogeneity, including preferential flow

519 paths, is required to produce statistically significant results.

\section{Acknowledgements}


530

531

532

533

\section{References}

Anderson, M.P., and W.W., Woessner. 1992. Applied Groundwater Modeling Simulation of Flow and Advective Transport. London: Academic Press.

Anderson, M.P. 2005. Heat as a ground water tracer. Ground Water 43, no. 6: 951-968. DOI:10.1111/j.1745-6584.2005.00052.x

ASCE (American Society of Civil Engineers). 2008. Standard guideline for fitting saturated hydraulic conductivity using probability density function. ASCE/EWRI 50-08. Reston, Virginia: ASCE.

Bennett, V,G.L., G.S., Weissmann, G.S, Baker, and D.W., Hyndman. 2006. Regional-scale assessment of a sequence-bounding paleosol on fluvial fans using ground-penetrating radar, eastern San Joaquin Valley, California. Bulletin of the Geological Society of America 118: 724732.

Berg, S.J., and W.A., Illman. 2011. Three-dimensional transient hydraulic tomography in a highly heterogeneous glaciofluvial aquifer-aquitard system. Water Resources Research 47, no. 10, W10507. DOI:10.1029/2011WR010616 
Bravo, H.R., F., Jiang, and R.J., Hunt. 2002. Using groundwater temperature data to constrain parameter estimation in a groundwater flow model of a wetland system. Water Resources Research 38, no. 8: 28-1-28-14. DOI:10.1029/2000WR000172

Burger, R.L., and K., Belitz. 1997. Measurement of anisotropic hydraulic conductivity in unconsolidated sands: A case study from a shoreface deposit, Oyster, Virginia. Water Resources Research 33, no. 6: 1515-1522. DOI:10.1029/97WR00570

Butler, Jr., J.J., G.C., Bohling, Z., Hyder, and C.D., McElwee. 1994. The use of slug tests to describe vertical variations in hydraulic conductivity. Journal of Hydrology 156: 137-162. DOI: 10.1016/0022-1694(94)90075-2

Cardenas, M.B., and X.-W., Jiang. 2010. Groundwater flow, transport, and residence times through topography-driven basins with exponentially decreasing permeability and porosity. Water Resources Research 46, no. 10. DOI:10.1029/2010WR009370

Chen, X. 2011. Depth-dependent hydraulic conductivity distribution patterns of a streambed. Hydrological Processes 25, no.2: 278-287. DOI:10.1002/hyp.7844

Constantz, J. 2008. Heat as a tracer to determine streambed water exchanges. Water Resources 
Deutsch, C.V., and A.G., Journel. 1998. GSLIB Geostatistical Software Library and User's Guide 2nd ed. New York: Oxford University Press.

Deutsch, C.V. 2007. A review of geostatistical approaches to data fusion. In Subsurface Hydrology: Data Integration for Properties and Processes, ed. D.W., Hyndman, F.D., Day-Lewis, and K., Singha, 7-18. Geophysical Monograph 171. Washington, D.C.: AGU. DOI:10.1029/171GM03

Domenico, P.A., and F.W., Schwartz. 1998. Physical and Chemical Hydrogeology 2nd ed. New York: Wiley.

Eggleston, J.R., S.A., Rojstaczer, and J.J., Peirce. 1996. Identification of hydraulic conductivity structure in sand and gravel aquifers: Cape Cod data set. Water Resources Research 32, no. 5: 1209-1222. DOI:10.1029/96WR00272

Eggleston, J.R., and S., Rojstaczer. 1998. Identification of large-scale hydraulic conductivity trends and influence of trends on contaminant transport. Water Resources Research 34, no. 9: 21552168. DOI:10.1029/98WR01475

Felletti, F., R., Bersezio, and M., Giudici. 2006. Geostatistical simulation and numerical upscaling, to 

model ground-water flow in a sandy-gravel, braided river, aquifer analogue. Journal of Sedimentary Research 76, no. 11: 1215-1229. DOI:10.2110/jsr.2006.091

Freeze, R.A., and J.A., Cherry. 1979. Groundwater. Englewood Cliffs, New Jersey: Prentice-Hall.

Gelhar, L.W. 1993. Stochastic Subsurface hydrology. Englewood Cliffs, New Jersey: Prentice Hall.

Guin, A., R., Ramanathan, R.W., Ritzi, Jr., D.F., Dominic, I.A., Lunt, T.D., Scheibe, and V.L., Freedman. 2010. Simulating the heterogeneity in braided channel belt deposits: 2. Examples of results and comparison to natural deposits. Water Resources Research 46, no. 4, W04516. DOI:10.1029/2009WR008112

Hess, K.M., S.H., Wolf, and M.A., Celia. 1992. Large-scale natural gradient tracer test in sand and gravel, Cape Cod, Massachusetts: 3. Hydraulic conductivity variability and calculated macrodispersivities. Water Resources Research 28, no. 8: 2011-2027. DOI:10.1029/92WR00668

Hu, S.G., S., Miyajima, D., Nagaoka, K., Koizumi, and K., Mukai. 2010. Study on the relation between groundwater and surface water in Toyohira-gawa alluvial fan, Hokkaido, Japan. In Groundwater Response to Changing Climate, ed. M., Taniguchi, and I.P., Holman, 141-157. AK 
591

Ingebritsen, S.E., W.E., Sanford, and C.E., Neuzil. 2006. Groundwater in Geologic Processes, 2nd ed. Cambridge: Cambridge University Press.

Jang, C.S., and C.W., Liu. 2004. Geostatistical analysis and conditional simulation for estimating the spatial variability of hydraulic conductivity in the Choushui River alluvial fan, Taiwan. Hydrological Processes 18, no. 7: 1333-1350. DOI:10.1002/hyp.1397

Jiang, X.W., L., Wan, X.S., Wang, S., Ge, and J., Liu. 2009. Effect of exponential decay in hydraulic conductivity with depth on regional groundwater flow. Geophysical Research Letters 36, no. 24.

Jiang, X.W., X.S., Wang, and L., Wan. 2010a. Semi-empirical equations for the systematic decrease DOI:10.1029/2009GL041251

in permeability with depth in porous and fractured media. Hydrogeology Journal 18, no. 4: 839850. DOI:10.1007/s10040-010-0575-3

Jiang, X.W., L., Wan., M.B., Cardenas, S. Ge, and X.S., Wang. 2010b. Simultaneous rejuvenation and aging of groundwater in basins due to depth decaying hydraulic conductivity and porosity.

\author{
Geophysical Research Letters 37, no. 5, L05403. DOI:10.1029/2010GL042387
}


Jussel, P., F., Stauffer, and T., Dracos. 1994. Transport modeling in heterogeneous aquifers: 1. Statistical description and numerical generation of gravel deposits. Water Resources Research 30, no. 6: 1803-1817. DOI:10.1029/94WR00162

Koltermann, C.E., and S.M., Gorelick. 1995. Fractional packing model for hydraulic conductivity derived from sediment mixtures. Water Resources Research 31, no. 12: 3283-3298. DOI:10.1029/95WR02020

Koltermann, C.E., and S.M., Gorelick. 1996. Heterogeneity in sedimentary deposits: a review of structure-imitating, process-imitating, and descriptive approaches. Water Resources Research 32, no. 9: 2617-2658. DOI:10.1029/96WR00025

Langevin, C.D., D.T., Thorne, Jr., A.M., Dausman, M.C., Sukop, and W., Guo. 2008. SEAWAT Version 4: A computer program for simulation of multi species solute and heat transport. Techniques and Methods 6, A22. Reston, Virginia: USGS.

Lee, S.Y., S.F., Carle, and G.E., Fogg. 2007. Geologic heterogeneity and a comparison of two geostatistical models: Sequential Gaussian and transition probability-based geostatistical simulation. Advances in Water Resources 30, no. 9: 1914-1932. 
621

Major, J.J., R.M., Iverson, D.F., McTigue, S., Macias, and B.K., Fiedorowicz. 1997. Geotechnical properties of debris-flow sediments and slurries, In Debris flow Hazards Mitigation: Mechanics, Prediction, and Assessment, ASCE Proceedings of First International Conference, ed. C.L. Chen, 249-259. San Francisco: ASCE.

Marion, A., A.I., Packman, M., Zaramella, and A. Bottacin-Busolin. 2008. Hyporheic flows in stratified beds. Water Resources Research 44, no. 9. DOI:10.1029/2007WR006079

Neton, M.J., J., Dorsch, C.D., Olson, and S.C., Young. 1994. Architecture and directional scales of heterogeneity in alluvial-fan aquifers. Journal of Sedimentary Research 64, no. 2b : 245-257.

\section{DOI:10.1306/D4267FA0-2B26-11D7-8648000102C1865D}

Nowak, M. and G., Verly. 2004. The practice of sequential Gaussian simulation. In Geostatistics Banff, Ed., O., Leuangthong, and C.V., Deutsch, 387-398. Netherlands, Dordrecht: Springer. DOI:10.1007/978-1-4020-3610-1_39

Ramanathan, R., A. Guin, R.W., Ritzi, Jr., D.F., Dominic, V.L., Freedman, T.D., Scheibe, and I.A., Lunt. 2010. Simulating the heterogeneity in braided channel belt deposits: 1. A geometric-based 

data of coarse gravel deposits. Journal of Hydrology 255 no. 1-4: 234-252. DOI:

Rubin, Y. 2003. Applied stochastic hydrogeology. New York: Oxford university press.

Rust, B.R. 1979. Facies Models 2. Coarse Alluvial Deposits. In Facies Models, ed. R.G., Walker, 11-21. Toronto: Geological Association of Canada.

inferred from hydrogeologic, thermal, seismic, and magmatic modeling constraints. Journal of Geophysical Research 109: B04204. DOI:10.1029/2003JB002855

Sakata, Y., and R., Ikeda. 2012. Quantification of longitudinal river discharge and leakage in an alluvial Fan by synoptic survey using handheld ADV. Journal of Japan Society of Hydrology and Water Resources 25, no. 2: 89-102 (in Japanese).

Sakata, Y., and R., Ikeda. 2013a. Regional mapping of vertical hydraulic gradient using uncertain well data: a case study of the Toyohira River alluvial fan, Japan. Journal of Water Resource and 
Sakata, Y., and R., Ikeda. 2013b. Depth dependence and exponential models of permeability in alluvial-fan gravel deposits. Hydrogeology Journal 21, no. 4: 773-786. DOI:10.1007/s10040013-0961-8

Sakata, Y. 2013. 5 Stochastic simulation of groundwater-flow and heat-transport. In Geostatistical reservoir modeling of trending heterogeneity specified in focused recharge zone: a case study of Toyohira River alluvial fan, Sapporo, Japan, 112-149. Ph.D. dissertation, Hokkaido University, Sapporo, Japan.

Thorne, D., C.D., Langevin, and M.C., Sukop. 2006. Addition of simultaneous heat and solute transport and variable fluid viscosity to SEAWAT. Computer and Geosciences 32: 1758-1768.

$$
\text { DOI:10.1016/j.cageo.2006.04.005 }
$$

Voss, C.L. 1984. A finite-element simulation model for saturated-unsaturated, fluid-densitydependent ground-water flow with energy transport or chemically-reactive single-species solute transport, Water-Resources Investigations Report 84-4369. Reston, Virginia: USGS.

Wang, K., P.Y., Shen, and A.E., Beck. 1989. A solution to the inverse problem of coupled 
Weissmann, G.S., S.F., Carle, and G.E., Fogg. 1999. Three-dimensional hydrofacies modeling based on soil survey analysis and transition probability geostatistics. Water Resources Research 35, no.

Woessner, W.W. 2000. Stream and fluvial plain ground water interactions: rescaling hydrogeologic

Woodbury, A.D., and L., Smith. 1988. Simultaneous inversion of hydrogeologic and thermal data: 2.

Yamaguchi, Y., and A., Nakamura. 1994. Change of permeability of shallow foundation for fill dams due to excavation and embankment. Journal of Groundwater Hydrology 36, no. 4: 423-438 (in Japanese). 
Zlotnik, V.A., M.B. Cardenas, and D. Toundykov. 2011. Effects of multiscale anisotropy on basin 


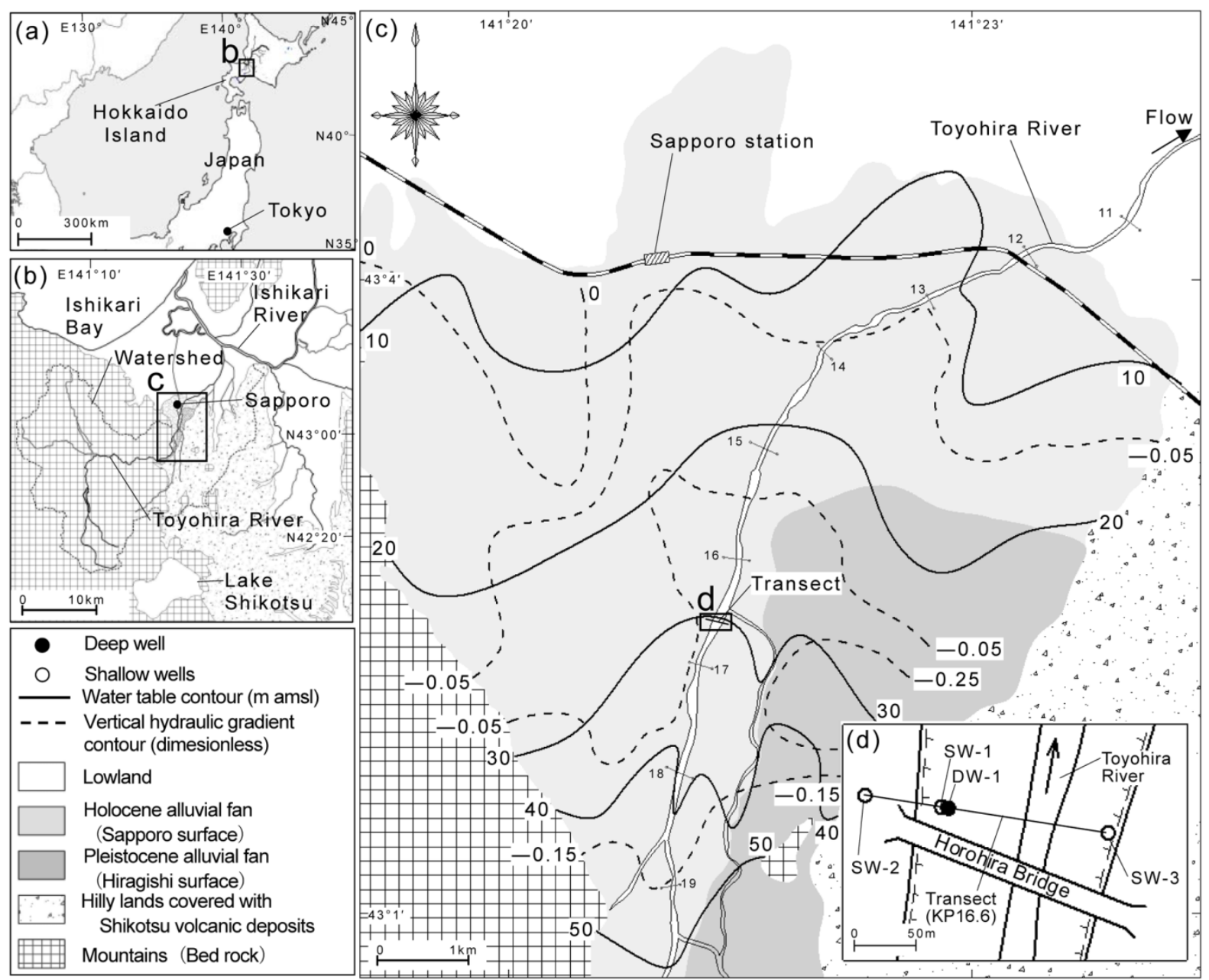

Figure 1 Location maps and topographic features of study area of Toyohira River alluvial fan. 


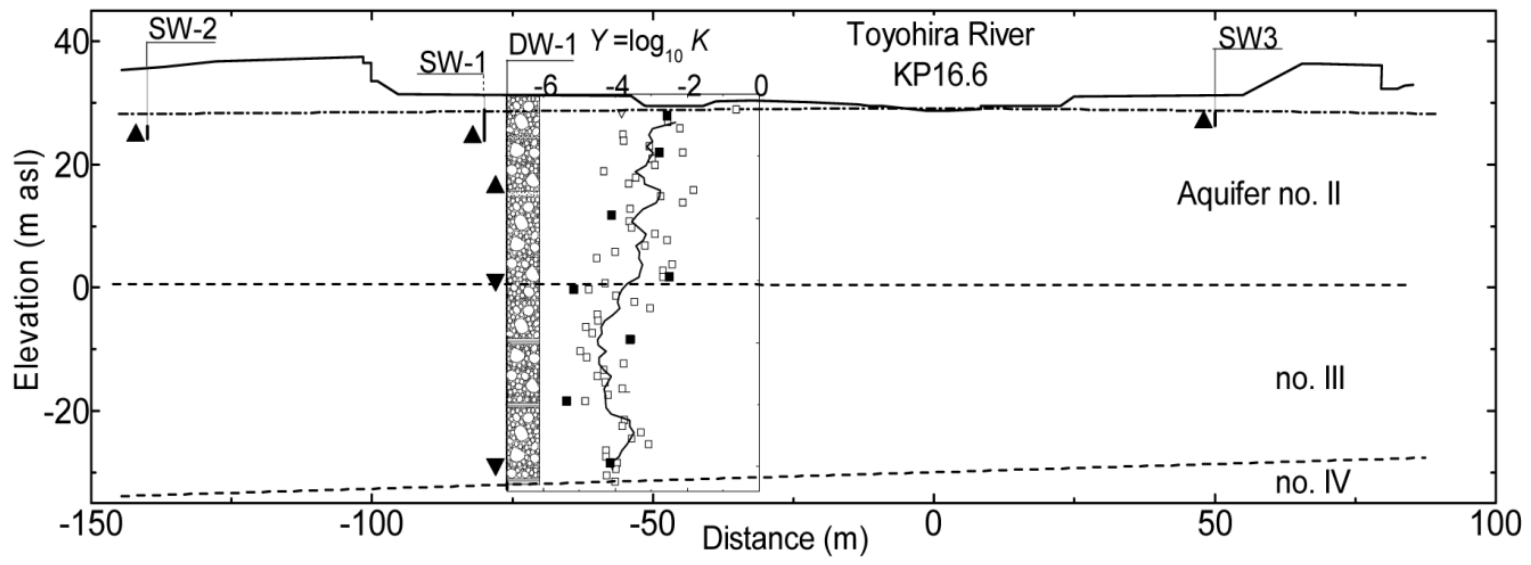

Figure 2 Cross section of the study area showing observation locations. Solid triangles represent water pressure and temperature observations, and inverted triangles are those of temperature alone. Aquifers II, III, and IV are described in the text. The vertical profile of $Y$ was taken from Sakata and Ikeda (2013b); solid squares, open squares, and solid line denote $Y$ values measured by slug tests, $Y$ values estimated from undisturbed cores, and moving averages of estimated $Y$, respectively.

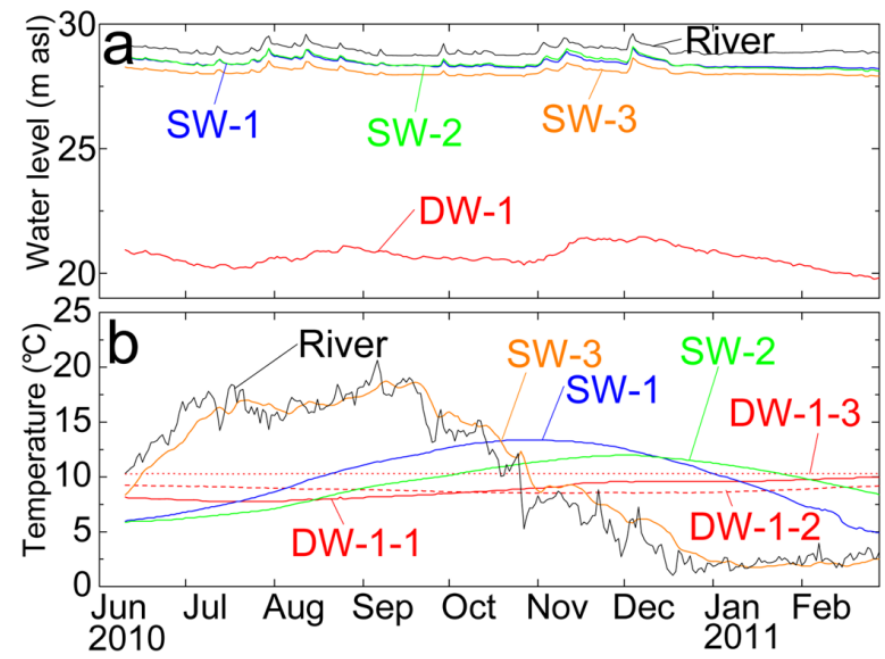

Figure 3 Daily mean variations of water level (a) and temperature (b) in the river and observation wells. 


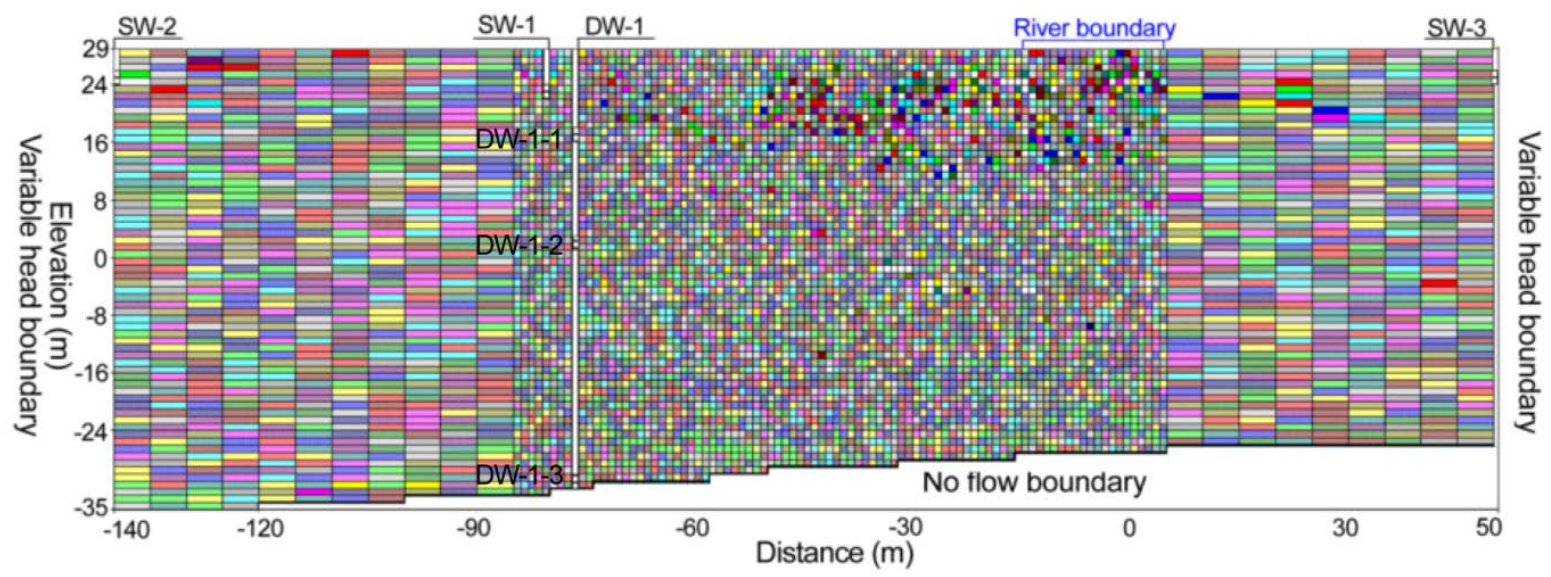

Figure 4 Cross-sectional simulation model of SEAWAT. The random color of each cell was assigned

701 from the realization of $K$.

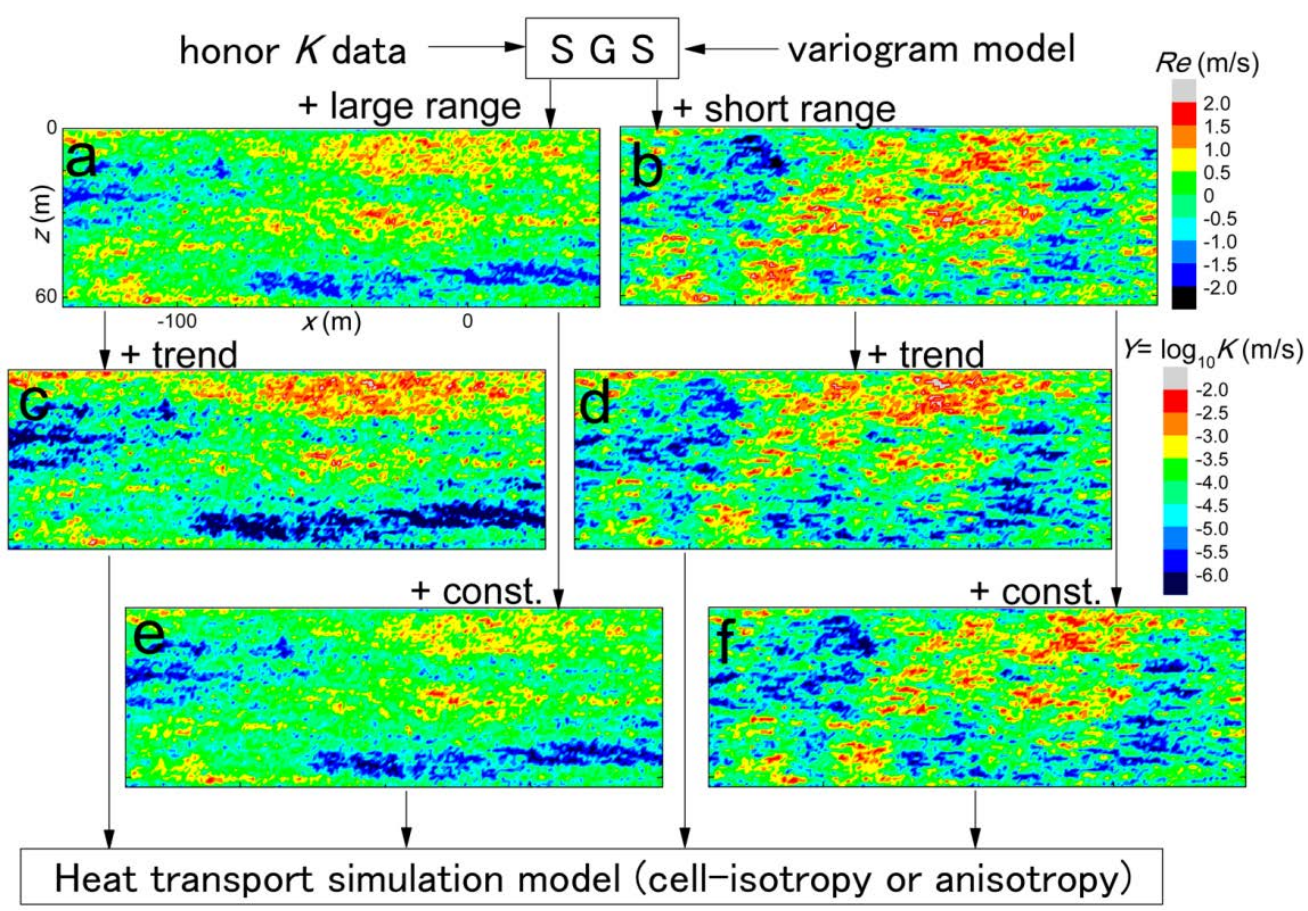

Figure 5 Conceptual flow chart showing the generating algorithm for the realization of the residuals

$R$ using large (a) and small (b) ranges, and of the logarithm of hydraulic conductivity $Y$ (c to f). 


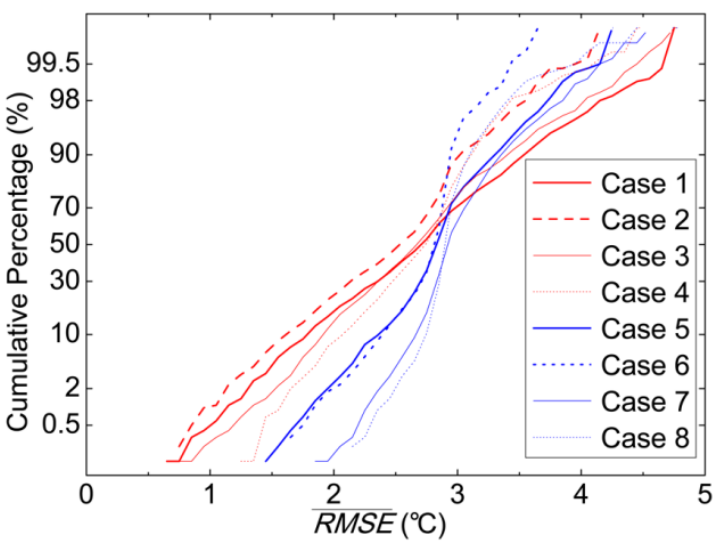

Figure 6 Cumulative percentage curves of $\overline{R M S E}$ for the eight simulation cases. Red lines indicate exponential decrease of $K$ and blues lines have constant mean change; bold and thin lines represent large and small variogram ranges, respectively, and solid and dotted lines indicate cell isotropy and anisotropy, respectively.
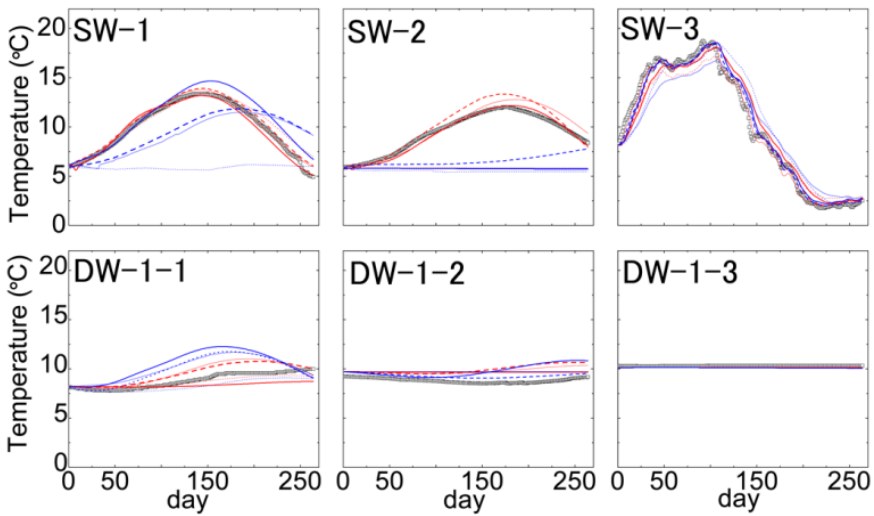

Figure 7 Calculated time series of groundwater temperature by extracted realizations of Min for the eight cases. Bold squares are observations, and color lines are the eight simulation cases denoted as in Fig. 6. 
718 Table 1 Summary of $\overline{R M S E}$ in 1000 realizations of each study case.

\begin{tabular}{|c|c|c|c|c|c|c|c|}
\hline \multirow{2}{*}{ Case } & \multicolumn{3}{|c|}{ Conditions } & \multicolumn{4}{|c|}{ Results } \\
\hline & Trend & Range & Cell & $M e$ & Var & Min & $N_{R M S E}$ \\
\hline 1 & exponential decay & large & isotropy & 2.76 & 0.47 & 0.66 & 4 \\
\hline 2 & & & anisotropy & 2.58 & 0.33 & 0.75 & 10 \\
\hline 3 & & small & isotropy & 2.73 & 0.35 & 0.62 & 2 \\
\hline 4 & & & anisotropy & 2.79 & 0.19 & 1.27 & none \\
\hline 5 & constant mean & large & isotropy & 2.89 & 0.15 & 1.43 & none \\
\hline 6 & & & anisotropy & 2.87 & 0.07 & 1.59 & none \\
\hline 7 & & small & isotropy & 2.96 & 0.10 & 1.87 & none \\
\hline 8 & & & anisotropy & 2.93 & 0.04 & 2.17 & none \\
\hline
\end{tabular}

